\title{
Malocclusion and deleterious oral habits among adolescents in a developing area in northeastern Brazil
}

\section{Erika Bárbara Abreu Fonseca Thomaz $^{(a)}$ \\ Maria Cristina Teixeira \\ Cangussu(b) \\ Ana Marlúcia Oliveira Assis(c)}

(a) Department of Public Health, Univ Federal do Maranhão, São Luís, MA, Brazil.

(b) School of Dentistry, Univ Federal da Bahia, Salvador, BA, Brazil.

(c) School of Nutrition, Univ Federal da Bahia, Salvador, BA, Brazil.
Declaration of Interests: The authors certify that they have no commercial or associative interest that represents a conflict of interest in connection with the manuscript.

Corresponding Author:

Erika Bárbara Abreu Fonseca Thomaz

E-mail: ebthomaz@globo.com

Submitted: May 19, 2012

Accepted for publication: Aug 13, 2012

Last revision: Sep 01, 2012

\begin{abstract}
Although malocclusions represent a serious public health issue, there is insufficient information about this problem in adolescents in Brazil, especially in poorer areas. The purpose of this cross-sectional study was to estimate the prevalence of facial alterations, dental malocclusions, and deleterious oral habits $(\mathrm{DOH})$ among adolescents in a developing area in northeastern Brazil and to test the hypothesis that the occurrence of $\mathrm{DOH}$ in infancy is associated with $\mathrm{DOH}$ during adolescence. The study included a probabilistic population-based sample of 2,060 Brazilian students aged 12-15 years. Facial characteristics (type of facial profile, facial symmetry, and passive lip sealing) and malocclusions (Angle and Dental Aesthetic Index, DAI) were evaluated. DOH in infancy and adolescence were evaluated by interviews with the parents and adolescents. Most adolescents presented with normal facial characteristics. The malocclusion prevalence (Angle) was $83 \%$. The DAI ranged from 13 to 69 (mean \pm SD: $25.9 \pm 7.7)$. Orthodontic treatment was necessary in $45.1 \%$ of the sample. The most prevalent $\mathrm{DOH}$ in adolescents were nail biting, object biting, cheek/lip biting, and bruxism, which were associated with finger sucking during infancy $(\mathrm{P}<0.05)$. We conclude that malocclusions and DOH are common among Brazilian adolescents and that finger sucking during infancy may be a good predictor of $\mathrm{DOH}$ occurrence during adolescence.
\end{abstract}

Descriptors: Malocclusion; Habits; Adolescent; Brazil.

\section{Introduction}

Malocclusions (MO) represent a relevant public health problem because of their high prevalence and the resulting aesthetic and functional impairment, leading to a negative impact on quality of life and high treatment cost for the patient..$^{1-4}$ Various studies have investigated the frequency and distribution of MO in young permanent dentition, ${ }^{3-5}$ but the use of different methods and indicators impairs the comparison of these results. Thus, the World Health Organization (WHO) recommends the use of the Dental Aesthetic Index (DAI) to standardize epidemiological data on MO. ${ }^{6}$ This index has good accuracy ${ }^{5}$ and is recommended for determining orthodontic treatment needs (OTN) in Brazil. ${ }^{7}$ However, the results still show discrepancies, ${ }^{1-3}$ and the influence of ethnic and sociocultural factors on the occurrence of MO cannot be ruled out. In this respect, the northeastern region of Brazil represents a particularly inter- 
esting area for the analysis of oral health conditions and orthodontic needs because of its socioeconomic and ethnic-cultural diversity ${ }^{8}$. In addition, deleterious oral habits $(\mathrm{DOH})$, which are one of the most important risk factors for the occurrence of $\mathrm{MO},{ }^{1,7}$ have been thoroughly studied in children but not in adolescents. ${ }^{7,-11}$

Therefore, the objectives of this study were to estimate the prevalence of facial alterations (FA), dental $\mathrm{MO}$, and $\mathrm{DOH}$ among adolescents from a developing area in northeastern Brazil and to test the hypothesis that the occurrence of $\mathrm{DOH}$ in infancy is associated with poor habits during adolescence.

\section{Methodology}

This study was approved by the ethics committee of the Federal University of Bahia (process 0122004). Students were only included in the study after signing an informed consent form.

A cross-sectional study was conducted that included adolescents of both genders, from 12 to 15 years old, who were regularly enrolled in primary and secondary schools in Salvador, Bahia, Brazil in 2004. The city of Salvador is located in the northeastern region of Brazil and has a population of approximately 3 million and a mean gross domestic product per capita of US $\$ 4,914.00$. It is characterized by a strong African ethnic-cultural influence. ${ }^{8}$

A probabilistic sample was obtained by conglomerate sampling in two stages, in which schools were the primary sampling unit, and the students were the secondary sampling unit. The sample size was estimated at 2,060 students, considering a prevalence of $\mathrm{MO}$ of $53.3 \%,{ }^{10}$ an alpha of $5 \%$, a sampling error of $3.5 \%$, the number of students of 196,532 , a design effect of 2 , and an addition of $32.6 \%$ owing to non-responses.

Thirty-three public schools and seven private schools $(10 \%$ of the teaching establishments) were selected by drawing lots. An equal number of students was randomly selected per school and per age, maintaining the proportion of students from public and private schools (13 students per age, corresponding to 52 students per school). If the student selected could not be contacted, the examiners returned to the school up to three times. After these attempts, the student was considered to be lost.

Students were excluded if they had mixed dentition, a history of orthodontic treatment, or problems that prevented clinical assessment; exclusions also included those whose parents/legal guardians did not sign a free and informed consent form and those who refused to be evaluated.

In a pilot study, a team of dentistry students underwent theoretical-practical training, and intraand inter-evaluator agreements (kappa) were evaluated. Only eight examiners with both agreements that were up to $85 \%$ were selected.

Data were collected using a questionnaire and orthodontic examination chart. The questionnaire was composed of two parts:

1. Each adolescent responded by providing data pertaining to:

- identification/sociodemographic characteristics (name, birth date, address, phone number, gender, skin color, reprobation history, household and family characteristics),

- oral habits (pacifier and finger sucking, mouth breathing, breastfeeding, bottle-feeding, nail biting, object biting such as a pencil, pen, ruler, toys, etc., lip/cheek biting, and tooth clenching/grinding; each was classified as yes or no).

2. The mother/legal guardian responded by providing data pertaining to:

- sociodemographic characteristics (household income, classified as low: $<2 \times$ the minimum wage $[\mathrm{MW}]$; medium: $2-5 \times \mathrm{MW}$; or high: $>5 \times \mathrm{MW}$; educational level of the household head, classified as low: illiterate through primary education not completed; medium: primary education completed through secondary education completed; or high: undergraduate studies not completed through graduate studies completed);

- health (history of diseases in childhood and adolescence for the student), and

- oral habits (duration of the habit: never, had the habit but stopped, or continues today).

The adolescents were interviewed and examined at their school between August and October 2004, 
according to WHO recommendations. ${ }^{6}$ Exams were done with both the adolescent and examiner seated in school chairs, in a face-to-face position, using natural light. The probe recommended by WHO was used to quantify the severity of MO.

The type of facial profile (concave, straight, mildly convex, or severely convex), facial symmetry (yes or no), and passive lip sealing (yes or no) were evaluated. The $\mathrm{DAI}^{6,10}$ and the Angle criteria were used to classify MO. ${ }^{10}$

Prevalence rates and the respective 95\% confidence intervals $(95 \% \mathrm{CI})$ were estimated as well as the mean $(\mu) \pm$ standard deviation $(\mathrm{SD})$. The Chisquare, Mann-Whitney, and Kruskal-Wallis statistical tests were used $(\alpha=5 \%)$. Statistical analysis was performed using Stata $9.0^{\circledR}$ software (StataCorp LP, College Station, USA).

\section{Results}

The sample included 2,060 students. Most of them were girls $(56.7 \%)$ and mulatto $(70.6 \%)$ or black $(24.4 \%)$, with a household income below $2 \times$ MW $(64.3 \%)$, but this frequency varied according to school type $(\mathrm{P}<0.01)$, as $43.9 \%$ of the adolescents from private schools had a household income $>5 \times$ MW, and $65.7 \%$ of those from public schools had a household income below $2 \times \mathrm{MW}$. Most of the students were from public schools $(84.2 \%)$.

We observed a predominance of adolescents with a mildly convex facial profile $(65.9 \%)$, facial symmetry $(98.2 \%)$, and passive lip sealing $(85.1 \%)$. The prevalence of $\mathrm{MO}$ according to the Angle classification was $83 \%$, with Class I MO being the most frequent. The DAI ranged from 13 to $69(\mu \pm$ SD: $26 \pm 7.7$ ), with a high prevalence of anterior dental crowding (56.8\%). OTN were noted for $45.1 \%$ of the adolescents. It was highly desired for $11.1 \%$ and mandatory for $11.7 \%$. Straight facial profile, lip sealing, OTN (as assessed with DAI), and mandibular overjet were most prevalent in public schools, but Class III MO, crowding, and maxillary and mandibular irregularities were most prevalent in private schools (Table 1).

The less aesthetic facial profiles (severely convex and concave) were most prevalent among adolescents with a high household income $(\mathrm{P}<0.01)$, in those whose parents/legal guardians had a high educational level $(\mathrm{P}=0.03)$, in those enrolled in private schools $(\mathrm{P}<0.01)$, and in white adolescents $(\mathrm{P}=0.02)$. The severely convex profile was higher among boys, whereas girls mainly presented with the concave profile $(\mathrm{P}<0.01)$. Facial asymmetry was more frequent among mulatto students $(\mathrm{P}<0.01)$ and those enrolled in public schools $(\mathrm{P}=0.07)$. On the other hand, the absence of passive lip sealing was more common among students in private schools $(\mathrm{P}<0.01)$.

Normal occlusion was higher among girls, and Class I and III MO were higher among boys $(\mathrm{P}=0.04)$. The proportion of Class II and III MO was higher among white adolescents and those enrolled in private schools when compared to black and mulatto students $(\mathrm{P}<0.01)$ and those enrolled in public schools $(\mathrm{P}<0.01)$. According to DAI, severe/very severe $\mathrm{MO}$ was more prevalent among students in public schools compared to those in private schools $(\mathrm{P}=0.01)$.

The most commonly reported $\mathrm{DOH}$ during infancy were pacifier $(63.3 \%)$ and finger $(14.4 \%)$ sucking. However, the current prevalence of these habits was low $(1.1 \%$ and $3.5 \%$, respectively). In contrast, the prevalence of nail biting $(60.3 \%)$, object biting $(55.2 \%)$, and cheek/lip biting $(46.1 \%)$ was high at the time of assessment. These habits were more frequent among girls $(\mathrm{P}<0.01)$. In addition, bruxism $(\mathrm{P}<0.01)$ and finger sucking $(\mathrm{P}=0.02)$ were most prevalent among adolescents in public schools $(\mathrm{Ta}-$ ble 2).

After testing the association between each of the DOH during infancy and adolescence, we observed that students who sucked their fingers during infancy showed a higher prevalence of $\mathrm{DOH}$ during adolescence (Table 3).

\section{Discussion}

A high prevalence of adolescents with normal facial characteristics but with $\mathrm{MO}$ and $\mathrm{DOH}$ was observed in the present study. We observed differences in $\mathrm{FA}, \mathrm{MO}$, and $\mathrm{DOH}$ between adolescents in private and public schools. In addition, finger sucking during infancy appeared to be a good predictor of the occurrence of other $\mathrm{DOH}$ during adolescence. 
Table 1 - Facial characteristics and malocclusion among adolescents in northeastern Brazil.

\begin{tabular}{|c|c|c|c|c|c|}
\hline & & \multirow{2}{*}{$\mathrm{n}$} & \multirow{2}{*}{$\begin{array}{c}\text { Private } \\
\%\end{array}$} & \multirow{2}{*}{$\begin{array}{c}\text { Public } \\
\%\end{array}$} & \multirow{2}{*}{$P$ value } \\
\hline & & & & & \\
\hline \multicolumn{6}{|c|}{ Facial characteristics } \\
\hline \multirow{4}{*}{ Type of facial profile } & Severely convex & 47 & 21.3 & 78.7 & $<0.01$ \\
\hline & Mildly convex & 1357 & 16.9 & 83.1 & \\
\hline & Straight & 405 & 7.0 & 93.0 & \\
\hline & Concave & 251 & 23.1 & 76.9 & \\
\hline \multirow{2}{*}{ Facial symmetry } & Yes & 2022 & 16.0 & 84.0 & 0.07 \\
\hline & No & 38 & 5.3 & 94.7 & \\
\hline \multirow{2}{*}{ Lip sealing } & Yes & 1752 & 14.8 & 85.2 & $<0.01$ \\
\hline & No & 308 & 21.9 & 78.1 & \\
\hline \multicolumn{6}{|c|}{ Dental malocclusion - Angle } \\
\hline \multirow{5}{*}{ Angle $^{a}$} & Normal & 347 & 10.1 & 89.9 & $<0.01$ \\
\hline & Class I & 824 & 14.9 & 85.1 & \\
\hline & Class II & 399 & 18.8 & 81.2 & \\
\hline & Class III & 465 & 19.1 & 80.9 & \\
\hline & $\mathrm{NI}$ & 25 & & & \\
\hline \multicolumn{6}{|c|}{ Dental malocclusion - DAI } \\
\hline \multirow{2}{*}{$\begin{array}{c}\text { Number of absent } \\
\text { anterior teeth }\end{array}$} & None & 1943 & 15.9 & 84.1 & 0.51 \\
\hline & $\geq 1$ & 117 & 13.7 & 86.3 & \\
\hline \multirow{2}{*}{ Dental crowding } & None & 890 & 8.1 & 91.9 & $<0.01$ \\
\hline & $1-2$ segments & 1170 & 21.7 & 78.3 & \\
\hline \multirow{2}{*}{ Anterior spacing } & None & 1332 & 14.9 & 85.1 & 0.11 \\
\hline & $1-2$ segments & 728 & 17.6 & 82.4 & \\
\hline \multirow{3}{*}{ Anterior diastema ${ }^{\circ}$} & None & 1611 & 15.4 & 84.6 & 0.81 \\
\hline & $\geq 1 \mathrm{~mm}$ & 409 & 14.9 & 85.1 & \\
\hline & $\mathrm{NI}$ & 40 & & & \\
\hline \multirow{2}{*}{$\begin{array}{l}\text { Maxillary } \\
\text { irregularity }\end{array}$} & None & 1144 & 11.1 & 88.9 & $<0.01$ \\
\hline & $\geq 1 \mathrm{~mm}$ & 916 & 21.7 & 78.3 & \\
\hline \multirow{2}{*}{$\begin{array}{l}\text { Mandibular } \\
\text { irregularity }\end{array}$} & None & 1085 & 9.9 & 90.1 & $<0.01$ \\
\hline & $\geq 1 \mathrm{~mm}$ & 975 & 22.4 & 77.6 & \\
\hline \multirow{2}{*}{ Maxillary overiet } & $<2 \mathrm{~mm}$ & 1070 & 17.3 & 82.7 & 0.06 \\
\hline & $\geq 3 \mathrm{~mm}$ & 990 & 14.2 & 85.8 & \\
\hline \multirow{2}{*}{ Mandibular overjet } & No & 1950 & 16.7 & 83.3 & $<0.01$ \\
\hline & Yes & 110 & 0.9 & 99.1 & \\
\hline \multirow{2}{*}{ Open bite } & No & 1857 & 16.1 & 83.9 & 0.30 \\
\hline & Yes & 203 & 13.3 & 86.7 & \\
\hline \multirow{3}{*}{ Molar relationshipa } & Normal & 1040 & 15.5 & 84.5 & 0.73 \\
\hline & Deviation & 1004 & 16.4 & 84.0 & \\
\hline & $\mathrm{NI}$ & 16 & & & \\
\hline \multirow{5}{*}{$\begin{array}{l}\text { Orthodontic } \\
\text { treatment need }\end{array}$} & None & 1118 & 17.1 & 82.9 & 0.01 \\
\hline & Elective & 455 & 17.4 & 82.6 & \\
\hline & Highly desired & 225 & 12.9 & 87.1 & \\
\hline & Mandatory & 239 & 9.6 & 90.4 & \\
\hline & $\mathrm{NI}$ & 23 & & & \\
\hline
\end{tabular}

DAI: Dental Aesthetic Index. ${ }^{a}$ No information (NI) was available for some students. 
Table 2 - DOH among adolescents in northeastern Brazil.

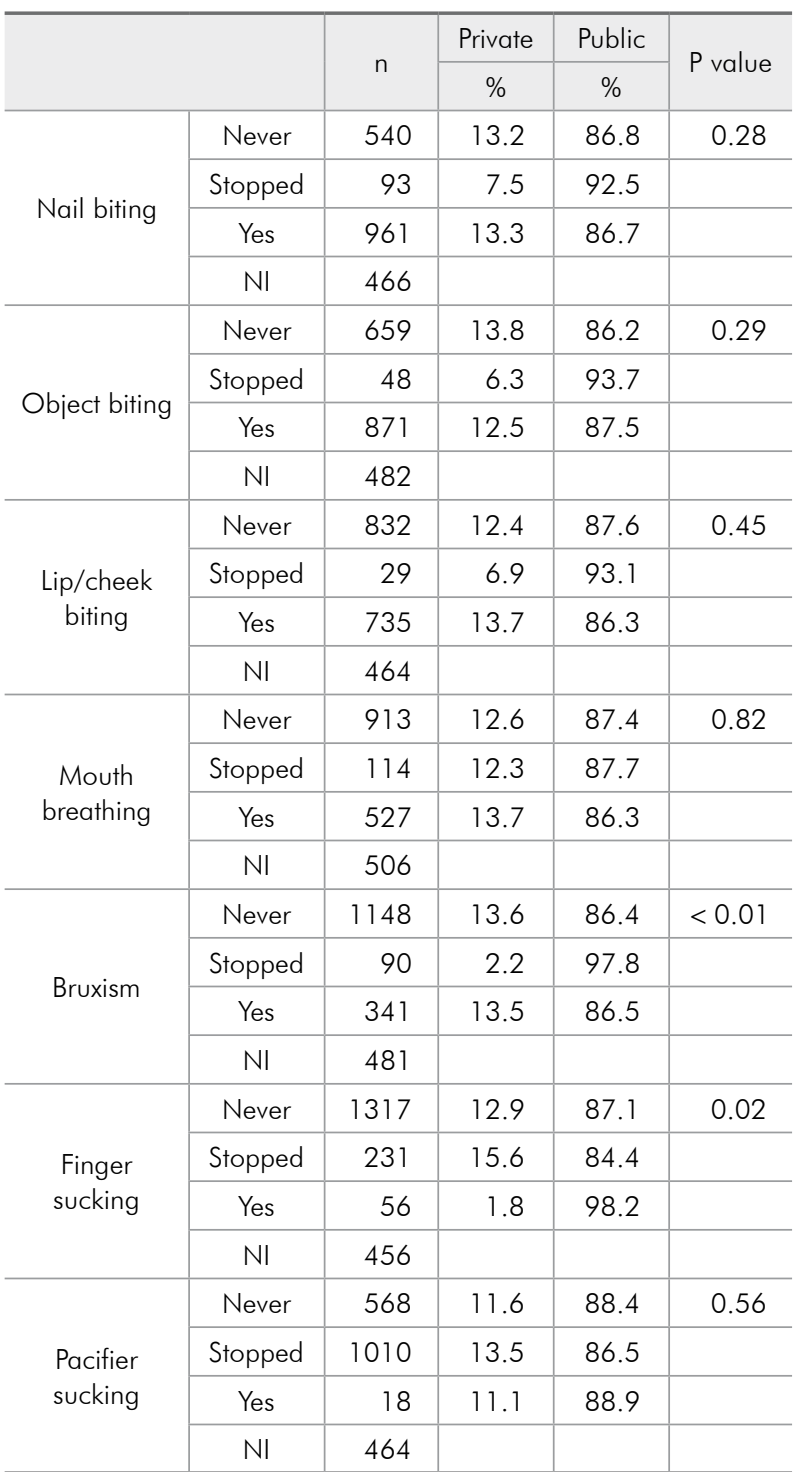

$\mathrm{NI}$ : no information was available.

Studies suggest that black individuals generally present with a more harmonic skeletal and dental pattern, whereas the prevalence of concave and severely convex facial profiles is higher among individuals of Asian origin and whites, respectively. ${ }^{11}$ These observations are consistent with those in the present study in which the population mainly consisted of mulatto and black individuals; we observed a predominance of the mildly convex profile.

Facial asymmetry $(1.9 \%)$ was rare in the adolescents studied, whereas dental midline deviation $(29.3 \%)$ was a frequent morphological characteris-
Table 3 - DOH during adolescence according to finger sucking during infancy.

\begin{tabular}{|c|c|c|c|c|c|c|}
\hline \multirow{3}{*}{\multicolumn{2}{|c|}{$\begin{array}{l}\text { DOH during } \\
\text { adolescence }\end{array}$}} & \multicolumn{4}{|c|}{ Finger sucking during infancy } & \multirow{4}{*}{$\begin{array}{c}P \\
\text { value }^{a} \\
<0.01\end{array}$} \\
\hline & & \multicolumn{2}{|c|}{ No } & \multicolumn{2}{|c|}{ Yes } & \\
\hline & & $\mathrm{n}$ & $\%$ & $\mathrm{n}$ & $\%$ & \\
\hline \multirow{2}{*}{ Nail biting } & No & 557 & 42.7 & 73 & 25.8 & \\
\hline & Yes & 747 & 57.3 & 210 & 74.2 & \\
\hline \multirow{2}{*}{ Object biting } & No & 595 & 46.3 & 108 & 37.9 & 0.01 \\
\hline & Yes & 691 & 53.7 & 177 & 62.1 & \\
\hline \multirow{2}{*}{ Cheek/lip biting } & No & 724 & 55.4 & 131 & 46.3 & $<0.01$ \\
\hline & Yes & 582 & 44.6 & 152 & 53.7 & \\
\hline \multirow{2}{*}{$\begin{array}{l}\text { Tooth clenching/ } \\
\text { grinding }\end{array}$} & No & 1024 & 79.4 & 207 & 73.7 & 0.03 \\
\hline & Yes & 266 & 20.6 & 74 & 26.3 & \\
\hline
\end{tabular}

${ }^{a}$ Chi-square test.

tic. Midline deviation was detected in $24 \%$ of Saudi adolescents aged 13-15 years in Jeddah City. ${ }^{12}$ In a population of North American adolescents, analysis of orthodontic records revealed facial asymmetry and dental midline deviation in $12 \%$ and $21 \%$ of those studied, respectively. ${ }^{13}$ The marked difference in the prevalence of facial asymmetry between the two populations is probably due to selection bias in studies involving populations referred for treatment, with overestimation of the occurrence of facial asymmetry in the American population. Unfortunately, no studies conducted on the Brazilian population are available for comparison.

At least one type of MO (Angle; especially Class I) was detected in $83 \%$ of the population studied. These results agree with the literature in which a rate of $82.1 \%$ to $91 \%$ has been reported..$^{1-4,10-12}$ Normal occlusion was mainly observed in girls, whereas Class I and III MO were more common among boys. Other authors have also observed differences between genders in the arrangement of the permanent first molars. ${ }^{12,14}$ We observed no differences in the prevalence of deep bite and Class II MO between genders. Similar results were seen in referral patients from Rio de Janeiro, Brazil. ${ }^{15}$

Furthermore, in the present study, the prevalence of Class II and III MO was higher among white students and students enrolled in private schools. To evaluate the association between income inequality and a public policy scale with oral health, the 
Brazilian oral health survey (SBBrasil) was used in 2002-2003 and included 23,573 15- to 19-year-old adolescents clustered in 330 municipalities. Results showed that neither the Gini coefficient nor public policies were significantly related to MO. ${ }^{16}$ These findings may reflect a deficiency in public policies related to MO control in Brazil, as orthodontic treatment was only recently legally included in the Brazilian National Health System, in December 2010. ${ }^{17}$

OTN according to DAI was observed in a high percentage of the sample $(45.1 \%)$. Brazilian studies have reported OTN rates of $53.3 \%$ among adolescents at the age of 12 , with higher rates $(77 \%)$ in the northeastern region. ${ }^{2}$ OTN were strongly indicated for $11.1 \%$ of the adolescents in the present study and mandatory for $11.7 \%$. These results are in agreement with Garbin et al. ${ }^{10}$ who observed defined and severe $\mathrm{MO}$ in $11 \%$ and $10.9 \%$, respectively, of 12-year-old students from Lins, SP, Brazil. We observed no differences in the OTN (as assessed by DAI) between genders, consistent with a previous study. ${ }^{1}$

We observed a predominance of severe and very severe cases among students in public schools, similar to the finding of another study. ${ }^{1}$ This finding is probably due to the fact that students in private schools have better access to dental treatment. Another possible explanation is the smaller proportion of lost permanent teeth among adolescents in private schools. In the population studied here, the loss of anterior permanent teeth was comparable with that observed in another Brazilian study ${ }^{2}$ and was higher among students in public schools.

The most frequent types of $\mathrm{MO}$ were anterior crowding, deviation of the anteroposterior molar relationship, maxillary overjet, and dental irregularity in alignment. High rates of these anomalies, especially dental crowding, have also been reported for students assessed in other studies. ${ }^{1,2,12}$ These findings support the observation that the frequency of dental crowding increases over time. An interesting reduction in spacing and increase in crowding in dental arches were observed in a long-term study of 308 adolescents from Iceland who were reexamined 25 years later. ${ }^{18}$

$\mathrm{DOH}$ are important environmental factors that may lead to MO. ${ }^{1,7}$ These habits disrupt muscular balance and bone growth, producing changes in the dental arch and occlusal characteristics. However, few studies have investigated the occurrence of $\mathrm{DOH}$ among adolescents. ${ }^{19}$ This is particularly interesting because persistence of $\mathrm{DOH}$ beyond the deciduous dentition appears to be associated with occlusal damage during adolescence. ${ }^{1,7,12}$ The most common DOH observed during adolescence were nail biting, object biting, and cheek/lip biting, which were more frequent among girls. Similar findings have been reported among 13- to 16-year-old students. ${ }^{9}$

An interesting finding of the present study was the relationship between the habit of finger sucking during infancy and nail biting, cheek/lip biting, object biting, and tooth grinding during adolescence. Pacifier and finger sucking were the most prevalent $\mathrm{DOH}$ in childhood, but not during adolescence. Similar results were also seen in Indians. ${ }^{9}$ Historically, non-nutritive sucking habits are associated with early infancy and are seen as natural in some societies. ${ }^{19}$ However, persistence of this habit is highly criticized within the social environment of these children..$^{20}$ Evidence indicates that these DOH are related to a complex mechanism of compensation and flight in such a way that a child with emotional and/or psychological problems finds an escape from pressures, tensions, frustrations, insecurity, and anxiety in these DOH. ${ }^{21}$ In this respect, the habit may change from finger sucking to nail biting or another DOH. There is evidence of an association between bruxism and tension, stress, and emotional disturbance, corroborating this idea. ${ }^{22}$ Therefore, special attention should be paid to children with a habit of finger sucking during infancy to prevent a future occurrence of other $\mathrm{DOH}$.

One limitation of the present study is its crosssectional design, which may result in memory bias. The classification of the duration of $\mathrm{DOH}$ may not have been optimal. However, broad cut-off points were used to minimize systematic errors. A high proportion of non-response for $\mathrm{DOH}$ was seen (around 25\%), probably owing to the shame in reporting these habits. However, the sample size was estimated considering an excess of $32.56 \%$. In addition, data were collected in the year 2004 and 
presented in 2012. Nevertheless, the criteria and indicators used are currently up to date. DAI is indicated by WHO as a universal criterion to classify MO. ${ }^{6}$ On the other hand, there was no evidence of a large change in dental occlusion in the Brazilian population during 2003-2010. A comparison of the $\mu( \pm$ SD) from DAI between $2003(24.1 \pm 10.2)$ and $2010(24.4 \pm 8.5)$ from the SBBrasil database shows similar values.

The strong points of our study are the population-based probabilistic sampling approach that increases the representativeness and precision of the estimates, the use of different strategies to characterize $\mathrm{MO}$, and concern regarding quality criteria for collecting the data to increase the internal validity of the study. In addition, to our knowledge, this is the first population-based study of $\mathrm{DOH}$ in adolescents from northeastern Brazil.

\section{Conclusion}

The prevalence of facial anomalies was low in the adolescents studied, but there was a high prevalence of dental MO and OTN. In addition, oral sucking

\section{References}

1. Frazão P, Narvai P. Socio-environmental factors associated with dental occlusion in adolescents. Am J Orthod Dentofacial Orthop. 2006 Jun;129(6):809-16.

2. Marques C, Couto G, Orestes-Cardoso S. Assessment of orthodontic treatment needs in Brazilian schoolchildren according to the Dental Aesthetic Index (DAI). Community Dent Health. 2007 Jul-Aug;24(3):145-8.

3. Shivakumar KM, Chandu GN, Subba Reddy VV, Shafiulla MD. Prevalence of malocclusion and orthodontic treatment needs among middle and high school children of Davangere city, India by using Dental Aesthetic Index. J Indian Soc Pedod Prev Dent. 2009 Oct-Dec;27(4):211-8.

4. Peres SHCS, Goya S, Cortellazzi KL, Ambrosano GMB, Meneghim MC, Pereira AC. Self-perception and malocclusion and their relation to oral appearance and function. Cienc Saude Colet. 2011 Oct;16(10):4059-66.

5. Costa RN, Abreu MHNG, Magalhães CS, Moreira AN. Validity of two occlusal indices for determining orthodontic treatment needs of patients treated in a public university in Belo Horizonte, Minas Gerais State, Brazil. Cad Saude Publica. 2011 Mar;27(3):581-90.

6. World Health Organization. Oral Health Surveys: basic methods. $4^{\text {a }}$ ed. Geneva: ORH/EPID; 1997. 66 p. habits were rare in the adolescents, but the prevalence of nail biting, object biting, cheek/lip biting, mouth breathing, and tooth clenching/grinding was high. In this respect, finger sucking during infancy appears to be a potential predictor of the occurrence of other DOH during adolescence. Thus, special attention should be given to children who suck their fingers during infancy to prevent the future occurrence of $\mathrm{DOH}$.

\section{Acknowledgements}

We thank the Conselho Nacional de Desenvolvimento Científico e Tecnológico (CNPq) for providing a doctoral fellowship (no. 140779/20035), Fundação de Amparo à Pesquisa do Estado da Bahia (FAPESB) for financing the study (grant no. 056/04), and the Fundação de Amparo à Pesquisa e ao Desenvolvimento Científico e Tecnológico do Estado do Maranhão (FAPEMA) for the Maranhão Talent award (no. 01013/08). We also thank FAPEMA for funding the translation of this article (Edital FAPEMA no. 004/2012).

7. Montaldo L, Montaldo P, Cuccaro P, Caramico N, Minervini G. Effects of feeding on non-nutritive sucking habits and implications on occlusion in mixed dentition. Int J Paediatr Dent. 2011 Jan;21(1):68-73.

8. Brasil. Instituto Brasileiro de Geografia e Estatística. Censo Demográfico 2000. Brasília: IBGE; 2000 [cited 2012 Apr 9]. Available from: http://www.ibge.gov.br/home/estatistica/populacao/censo2000/populacao/censo2000_populacao.pdf.

9. Shetty SR, Munshi AK. Oral habits in children - a prevalence study. J Indian Soc Pedod Prev Dent. 1998 Jun;16(2):61-6.

10. Garbin AJÍ, Perin PCP, Garbin CAS, Lolli LF. Malocclusion prevalence and comparison between the Angle classification and the Dental Aesthetic Index in scholars in the interior of São Paulo state - Brazil. Dental Press J Orthod. 2010 JulAug;15(4):94-102.

11. Owens EG, Goodacre CJ, Loh PL, Hanke G, Okamura M, Jo $\mathrm{KH}$, et al. A multicenter interracial study of facial appearance. Part 2: A comparison of intraoral parameters. Int J Prosthodont. 2002 May-Jun;15(3):283-8.

12. Murshid ZA, Amin HE, Al-Nowaiser AM. Distribution of certain types of occlusal anomalies among Saudi Arabian adolescents in Jeddah city. Community Dent Health. 2010 Dec;27(4):238-41. 
13. Sheats RD, McGorray SP, Musmar Q, Wheeler TT, King GJ. Prevalence of orthodontic asymmetries. Semin Orthod. 1998 Dec;4(3):138-45.

14. Magnani MBBA, Nouer DF, Nouer PRA, Pereira-Neto JS, Garbui IU, Böeck EM. Assessment of the nasolabial angle in young Brazilian black subjects with normal occlusion. Braz Oral Res. 2004 Jul-Sep;18(3):233-7.

15. Marques LS, Armond MC, Ramos-Jorge ML, Andrade RGV, Bolognese AM. Correlations between dentoskeletal variables and deep bite in Class II Division 1 individuals. Braz Oral Res. 2011 Jan-Feb;25(1):56-62.

16. Celeste RK, Nadanovsky P. How much of the income inequality effect can be explained by public policy? Evidence from oral health in Brazil. Health Policy. 2010 Oct;97(2-3):250-8.

17. Brasil. Ministério da Saúde. Portaria ${ }^{\circ} 718$, de 20 de dezembro de 2010. Brasília: Ministério da Saúde; 2010 [cited 2012 Apr 9]. Available from: http://bvsms.saude.gov.br/bvs/saudelegis/ sas/2010/prt0718_20_12_2010.html.
18. Jonsson T, Magnusson TE. Crowding and spacing in the dental arches: long-term development in treated and untreated subjects. Am J Orthod Dentofacial Orthop. 2010 Oct;138(4):384-7.

19. Sertório SCM, Silva IA. The symbolic and utilitarian facets of pacifiers according to mothers. Rev Saude Publica. 2005 Apr;39(2):156-62. Portuguese.

20. Salah A. Mothers' attitude toward digit sucking habits in children of United Arab Emirates. Int J Orofacial Myology. 2007 Nov;33(1):37-46.

21. Morley DS. Psychophysiological reactivity to stress in nail biters. Int J Neurosci. 2000 Jul-Aug;103(1-4):139-54.

22. Renner A, Silva A, Rodriguez J, Simões V, Barbieri M, Bettiol $\mathrm{H}$, et al. Are mental health problems and depression associated with bruxism in children? Community Dent Oral Epidemiol. 2012 Jun;40(3):277-87. 